\title{
Purchase behaviour of consumer towards organic vegetables
}

\author{
B. NAVANEETHAM AND M. CHANDRAKUMAR
}

Received : 25.05.2016; Revised : 16.08.2016; Accepted : 03.09.2016

\begin{abstract}
Organic F and V sector is at nascent stage in India and has become one of the dynamic growing sectors in recent times. Increasing organic awareness and access to organic markets are developing at present as Indian consumers become more health conscious and begin to set out the importance diet and the increased rate of heart disease, obesity and diabetes with the population. Also, there is a burgeoning interest in avoiding chemical residues in foods among the population. The overall objective of the study was to analyze the consumer purchase behaviour. The study was carried out with 140 consumers. The acquired raw data were analyzed using appropriate statistical tools like conventional analysis. Results interpreted that majority $(85.71 \%)$ of the respondents opined the reason for purchase of organic vegetable was "Good for health because no chemicals and to avoid diseases". Majority of the respondents (94.29\%) preferred place for purchase of organic vegetables is organic outlet. About 89.00 per cent of the respondents purchase the organic vegetables weekly. About 74.00 per cent of the respondents purchase more of organic vegetables. It is evident that 80.00 per cent of the respondents reported that their preferred vegetables are available in the store. About 42.00 per cent were willing to pay 10 per cent higher than existing organic vegetables price. Highest monthly expenditure spent on food was Rs. 12,909 whose share on expenditure of organic vegetables was 33.75 per cent to that of total expenditure on food.
\end{abstract}

KEY WORDS : Organic vegetables, Purchase behaviour, Willingness to pay, Chemical residue free

How to cite this paper : Navaneetham, B. and Chandrakumar, M. (2016). Purchase behaviour of consumer towards organic vegetables. Internat. J. Com. \& Bus. Manage, 9(2) : 141-147. DOI: 10.15740/HAS/IJCBM/9.2/141-147.

Email: mchandrakumar1975@gmail.com 